\title{
Client Satisfaction and Outcome Comparisons of Online and Face-to-Face Counselling Methods
}

\author{
Lawrence Murphy, Paul Parnass, Daniel L. Mitchell, \\ Rebecca Hallett, Paula Cayley, and Samantha Seagram
}

Lawrence Murphy is co-founder of Worldwide Therapy Online and a director, clinician and trainer with the company. He holds an MA from the University of British Columbia. Paul Parnass is a counsellor and trainer with Worldwide Therapy Online Inc. and runs his own private online practice. He holds an MSW from the University of Toronto. Daniel Mitchell is co-founder of Worldwide Therapy Online and a director, clinician and trainer with the company. He holds an MA from the University of British Columbia. Rebecca Hallett is an associate professor in the department of Environmental Biology at the University of Guelph. Paula Cayley is the CEO of Interlock, a division of PPC Worldwide. Samantha Seagram is Manager of Client Care with Interlock, a division of PPC Worldwide.

Correspondence to Lawrence Murphy, Worldwide Therapy Online Inc., 18 Mont Street, Guelph Ontario, Canada N1H2A4. E-mail: lmurphy@privacemail.com

\section{Abstract}

This article compares Global Assessment of Function (GAF) and Client Satisfaction Survey scores for clients receiving either face-to-face or online counselling. Clients were assessed by phone and then assigned to one of the two modalities. Analyses of variance were conducted with $\alpha=0.05$, to examine differences between counselling modalities. No significant differences were found for degree of change in GAF between assessment and closing between the two modalities. Some differences were found in Client Satisfaction Scores. Implications for screening and social work practice are discussed.

Keywords: Social work and IT, evidence-based practice, research and evaluation, online counselling, e-mail therapy

\section{Literature review}

Cybercounselling is a field that has seen tremendous growth in the past ten years (Barak et al., 2008). With advances in technology and widespread use of the internet, more and more clients are turning to cybercounselling (Mallen et al., 2003). 
Various forms of technology are being used to deliver mental health services online. Online support groups, counselling via webcam and asynchronous online counselling are examples. With the emergence of cybercounselling, the authors of this paper propose to compare its effectiveness to face-to-face counselling.

There is a growing body of cybercounselling literature (Murphy and Mitchell, 1998; Collie et al., 2000; Hsiung, 2002; Tyler and Sabella, 2003; Kraus et al., 2004; Mitchell and Murphy, 2004; Derrig-Palumbo and Zeine, 2005; Murphy et al., 2008). Murphy and Mitchell (1998) explored the challenges, advantages and ethical issues when considering the delivery of cybercounselling services. In addition, they proposed a set of therapeutic techniques known as 'Presence Techniques' that allow communication of tone of voice and non-verbal information in text. For example, Emotional Bracketing (Murphy and Mitchell, 1998; Collie et al., 2000) is a technique wherein one places the emotions associated with a statement in square brackets after the statement itself. One might write 'I am wondering how you are feeling not having heard from you in several weeks [feeling concerned]'. Without the bracketing, the client may misinterpret the counsellor's statement as having a sub-text of disappointment or anger. The bracketing provides the client with the appropriate tone with which to read the counsellor's statement.

Cybercounselling has been the subject of many non-quantitative studies (Chechele and Stofle, 2003; Luce et al., 2003) and qualitative review analyses (e.g. Stofle, 2002), but research comparing the effectiveness of face-to-face and cybercounselling is limited.

Barak et al. (2008) conducted an extensive meta-analysis of ninety-two studies examining internet-based psychotherapeutic interventions involving a total of 9,764 clients. The mean weighted effect size was 0.53 (medium effect) for internet-based interventions, which is similar to the average effect size in face-to-face therapy. The authors concluded that internet based therapy on the average is as effective or nearly as effective as face-to-face therapy' (Barak et al., 2008, p. 30). However, meta-analyses have their limitations, including the file drawer effect, in which researchers tend not to publish negative results, creating a bias towards stronger effects when pooled.

Day and Schneider (2002) compared the effectiveness of face-to-face with audio and video counselling with eighty clients. Clients were assigned to one of three groups, which each received five counselling sessions using Cognitive Behavioural techniques. Using three sub-scales of the Vanderbilt Psychotherapy Process Scale, the Brief Symptom Inventory, the Global Assessment of Function Scale and the Target Complaints method, the authors concluded that the differences in process and outcome of the counselling modalities were minor and all were clinically promising compared with an untreated control group.

Several studies have examined the development of the relationship between therapist and client. Cook and Doyle (2002) found that the 
working alliance was strongly established in both online and face-to-face settings when comparing the Working Alliance Inventory (WAI) scores of a primarily female sample of fifteen online clients with a representative sample of face-to-face clients used in earlier studies. The authors note that despite the limitation of this small self-selected sample of online clients, 'working alliance levels demonstrate that participants felt a collaborative, bonding relationship with therapists, and comments overwhelmingly indicated participants' belief that online therapy was a positive experience with unique advantages over face-to-face counselling' (Cook and Doyle, 2002, p. 102).

Session impact and the client-therapist alliance in asynchronous cybercounselling were examined in therapist/client dyads by Reynolds et al. (2006) and compared to previously published research using the same measures for face-to-face counselling (Cohen and Kerr, 1998). Online therapists rated their exchanges as 'deeper and smoother' compared to face-to-face therapists (Reynolds et al., 2006, p. 164). Preliminary results suggested that 'online clients provided similar session impact and therapeutic alliance ratings compared to face-to-face clients' (Reynolds et al., 2006, p. 164).

Mallen et al. (2003) examined differences in the early stages of a relationship between two strangers interacting online versus face to face. Undergraduate students were placed into thirty-two pairs and randomly assigned to a thirty-minute conversation with a partner in either a face-to-face or internet chat program. The authors concluded that 'the face-to-face group felt more satisfied with the experience and experienced a greater degree of closeness and self-disclosure with their partner' (Mallen et al., 2003, p. 155). Both groups had equivalent levels of emotional understanding of their partner, but face-to-face groups reported higher levels of emotions. There are several limitations to this study. Conversations were limited to thirty minutes, no counsellors or therapists were used in the study, and students received extra credit for their participation in the study.

Client satisfaction with online counselling is influenced by the client's comfort and familiarity. Rochland et al. (2004) found that participants in face-to-face counselling evaluated their counselling experience more favourably than online participants. However, significant correlations were found between counselling modality and traditional help-seeking attitudes, comfort with e-mail and interest in counselling services. This study was also limited because it involved a relatively homogeneous sample of college students.

Liebert et al. (2006) studied a group of eighty-one primarily female clients using online services examining self-reported therapeutic alliance and satisfaction variables, compared to past face-to-face studies by McMurtry and Hudson (2000) and Busseri and Tyler (2003). Liebert et al. found that the more hours respondents spent online, the more likely they were to make use of online counselling. The authors concluded that online clients 'were 
satisfied with their relationships and treatment online, but not as satisfied as clients who have undergone traditional face-to-face counselling' (Liebert et al., 2006, p. 80).

Convenience, privacy and anonymity have been found to be the most frequent reasons for using internet counselling services (Liebert et al., 2006), and have been suggested as key online counselling advantages (Hamburger and Ben-Artzi, 2000). Liebert et al. speculated that "people who are especially sensitive to the presence of others, who have experienced emotional trauma, social marginalization, or judgment from others may need to communicate without fear of a listener's first reaction' (Liebert et al., 2006, p. 83).

There are limited studies comparing the effectiveness of face-to-face and online counselling. Most of these studies are limited by one or more factors, including sample size and comparison of online clients with face-to-face clients from different studies. That said, the studies reviewed above concluded that cybercounselling shows promise.

\section{Methodology}

Interlock is a Canadian Employee and Family Assistance Program provider that has been helping Canadians to be successful in the workplace since 1977. The company provides various services, including individual counselling, to more than 350 organizations in Canada. Services are provided to employees and their immediate family members.

Therapy Online is the world's first online clinical counselling service, having been founded in 1995 . Therapy Online began sub-contracting with Interlock to provide online counselling for their clients in April 2006. Only Therapy Online counsellors provide online counselling and Interlock counsellors provide face-to-face counselling, without overlap.

Both agencies employ counsellors with a minimum of a Master's degree and ten years' counselling experience. All counsellors working online have specialized training through Therapy Online's training arm (Murphy et al., 2008). Counsellors are a mixed group of males and females; however, five of seven of Therapy Online's counsellors are social workers, as are a significant portion of Interlock's.

In Canada, social workers play a significant role in the provision of counselling services. To become a social worker in Canada, one must attend an accredited school of social work and the title of 'social worker' can only be used by College of Social Workers members. The social workers in this study all hold an MSW and belong either to the Ontario College of Social Workers and Social Service Workers or to the British Columbia Board of Registration for Social Workers.

Interlock employs two assessment tools with both face-to-face and online clients: the Global Assessment of Function (GAF) and a Client Satisfaction 
Survey (CSS). Results from these tools were used to compare the effectiveness of the counselling modalities.

The Global Assessment of Functioning (GAF), based on the widely used Global Assessment Scale (Endicott et al., 1976), was included as axis V in the revised third edition of the Diagnostic and Statistical Manual (DSM-III-R; American Psychiatric Association, 1987) and has been retained with only minor revisions in DSM-IV-TR. It is widely used in facilities in North America because 'it is a universally recognized, easy to do measure of functioning' (J. Mogk, Clinical Coordinator, Maple Ridge Treatment Centre, personal communication, 18 November 2008).

Critics of the GAF question its reliability. Bacon et al. (2002) asked three raters with high reliability to classify the reasons given by eight clinicians for eighty GAF ratings. Their findings suggest that the GAF ratings were strongly influenced by factors other than adaptive functioning or symptom severity.

Several studies have been published, emphasizing the reliability of the GAF. Ramirez et al. (2008) examined the degree of agreement between patients and professionals using the GAF. In their study, the GAF was provided to 191 young adult psychiatric outpatients, and professionals treating them, before and after treatment. The Structured Clinical Interview for DSM-1V was used to asses Axis 1 and Axis 11 disorders. They found that there was agreement between patients' and professionals' ratings on the GAF before and after treatment.

Startup et al. (2002) assessed patients who were suffering from schizophrenia and admitted to hospital, at admission, six and twelve-month follow-up, using the GAF, the Scale for the Assessment of Positive Symptoms, the Assessment of Negative Symptoms and the Social Behavioural schedule. They found that GAF ratings correlated highly with the other ratings at both six and twelve-month follow-ups. Though these correlations were not the same at the initial assessment, inter-rater reliabilities for the measures were good. They concluded the GAF can be rated reliably after minimal training for clients other than those experiencing acute psychotic episodes.

The Employee Assistance Society of North America (EASNA) recommends that counsellors use the GAF and Interlock, having received EASNA/COA accreditation, encourages its counsellors to use the GAF as one of their main tools to assess client change. Consequently, GAF data were readily available for the present study.

The GAF is a numeric scale ( 0 through 100$)$ used by mental health clinicians to rate the social, occupational and psychological functioning of adults. It supplements existing data about a client's symptoms and helps predict outcomes of treatment. Once the GAF is completed, clinicians indicate the GAF rating within this 100-point range, using their clinical judgment and comparison with other clients.

The CSS consists of a series of thirteen questions. Its reliability and validity have not been tested. However, it is the tool used by Interlock in 
assessing both online and face-to-face clients and was thus the data available to the authors. Clients are asked to indicate the degree to which they agree or disagree with a series of statements using a Likert-like scale from 1 (strongly disagree) to 5 (strongly agree).

The survey is broken into two sections. The first is entitled Quality of Your Experience and covers eight questions. The second is entitled Program Effectiveness and covers the last five questions. This latter section is completed if the client is an employee but not if the client is an employee's family member. The rationale is that employers are only interested in reports on the responses of their employees for this material.

Of the thirteen questions, ten relate specifically to the counselling experience and three relate to business aspects of the client's relationship with Interlock. These latter questions were removed, leaving ten questions to be analysed.

Between April 2006 and May 2008, forty-five online clients completed the CSS. A convenience sample of forty-three face-to-face clients, selected from that group of individuals who completed counselling between April 2006 and May 2008, was used as a comparison group. Ethical review was completed by the authors in accordance with the ethical requirements for research laid out by the Canadian Counselling Association (CCA, 2007) and the Ontario College of Social Workers and Social Service Workers (OCSWSSW, 2008), of which the two principal researchers are members.

For online clients, twenty-six received an initial and a closing GAF score. This group was compared to a convenience sample of 101 face-to-face clients who received counselling during the same period.

Clients contact Interlock by phone and are screened by intake workers. Appropriate clients are offered counselling online and those who choose it receive counselling from Therapy Online's Affiliate Counsellors. Thus, the pool of clients from which face-to-face and online clients are drawn is the same, although there is a selection process. That said, the two groups are very similar. There were slight differences in gender breakdown (27 per cent of online clients were male compared to 24 per cent of face-to-face clients) and average age (online clients averaged forty-two years of age whereas face-to-face clients averaged forty-four years of age). Neither of these differences is unexpected with a convenience sample. In our experience working online, clients tend to be slightly younger and there is typically a higher proportion of male clients. The reasons for this latter phenomenon deserve more attention in the research but, in our experience, male clients say they favour online work because of the anonymity.

There were no differences between the two groups in terms of presenting problems. Common presenting problems in the Canadian EAP environment include work stress, separation and divorce, anxiety and depression and parenting. 
Analyses of variance (ANOVA) were conducted using PROC GLM (SAS v 9.1, SAS Institute, Cary, NC), with $\alpha=0.05$, to examine differences between counselling modalities for GAF assessments and CSS questionnaire responses.

\section{Results}

\section{Client Satisfaction Survey}

Client responses to the satisfaction survey, ranging from 1 to 5 , were compared based on counselling modality.

After reviewing the data, it became apparent that three clients had scores that were well outside the range of the general client population. Their scores were almost entirely in the 1 (strongly disagree) to 2 (disagree) range. Given that the field of online counselling is new and that screening of clients for appropriateness for the modality is in its infancy, we reanalysed the data with these three outliers removed.

Results are summarized in the two tables. Table 1 shows the data with all clients included. Table 2 shows the data with the outliers removed.

\section{Global Assessment of Function}

Clients are assigned a GAF score by their counsellor after the initial assessment and again at the close of counselling. A two-factor analysis of variance was conducted to examine the effects of assessment timing, counselling modality and their interaction on GAF scores. Results are summarized in Table 3.

Table 1 Client satisfaction survey results (all clients)

\begin{tabular}{|c|c|c|c|}
\hline Question & $\begin{array}{l}\text { Online } \\
\text { mean } \pm S E\end{array}$ & $\begin{array}{l}\text { Face-to-face } \\
\text { mean } \pm S E\end{array}$ & $P$ \\
\hline $\begin{array}{l}\text { 1. My counsellor helps/helped me feel comfortable in dis- } \\
\text { cussing my problems }\end{array}$ & $4.5 \pm 0.1$ & $4.6 \pm 0.1$ & NS \\
\hline $\begin{array}{l}\text { 2. My counsellor's efforts and suggestions are helping/ } \\
\text { helped me develop a plan for addressing my problems }\end{array}$ & $4.2 \pm 0.1$ & $4.4 \pm 0.1$ & NS \\
\hline $\begin{array}{l}\text { 3. My counsellor has/had the skills and expertise to assist } \\
\text { me with my concerns }\end{array}$ & $4.3 \pm 0.1$ & $4.5 \pm 0.1$ & NS \\
\hline $\begin{array}{l}\text { 4. My overall counselling experience with Interlock is/was } \\
\text { positive }\end{array}$ & $4.2 \pm 0.1$ & $4.7 \pm 0.1$ & 0.017 \\
\hline 5. My experience with the EAP meets/met my expectations & $4.1 \pm 0.2$ & $4.5 \pm 0.1$ & 0.035 \\
\hline 6. I feel this is a valuable benefit & $4.3 \pm 0.2$ & $4.8 \pm 0.1$ & 0.013 \\
\hline $\begin{array}{l}\text { 7. The issue(s) that led me to seek assistance interfered with } \\
\text { my home life }\end{array}$ & $4.2 \pm 0.1$ & $4.6 \pm 0.1$ & 0.026 \\
\hline 8. The assistance I received made things better at home & $3.8 \pm 0.2$ & $4.1 \pm 0.2$ & NS \\
\hline $\begin{array}{l}\text { 9. The issue(s) that led me to seek assistance interfered with } \\
\text { my work life }\end{array}$ & $3.6 \pm 0.2$ & $4.1 \pm 0.2$ & 0.049 \\
\hline 10. The assistance I received made things better at work & $3.3 \pm 0.2$ & $3.8 \pm 0.2$ & NS \\
\hline
\end{tabular}

NS $=$ no significant difference between counselling modalities, at $P \leq 0.05$. 
Table 2 Client satisfaction survey results (outliers removed)

\begin{tabular}{|c|c|c|c|}
\hline Question & $\begin{array}{l}\text { Online } \\
\text { mean } \pm \text { SE }\end{array}$ & $\begin{array}{l}\text { Face-to-face } \\
\text { mean } \pm S E\end{array}$ & $P$ \\
\hline $\begin{array}{l}\text { 1. My counsellor helps/helped me feel comfortable in discuss- } \\
\text { ing my problems }\end{array}$ & $4.6 \pm 0.1$ & $4.6 \pm 0.1$ & NS \\
\hline $\begin{array}{l}\text { 2. My counsellor's efforts and suggestions are helping/helped } \\
\text { me develop a plan for addressing my problems }\end{array}$ & $4.4 \pm 0.1$ & $4.4 \pm 0.1$ & NS \\
\hline $\begin{array}{l}\text { 3. My counsellor has/had the skills and expertise to assist me } \\
\text { with my concerns }\end{array}$ & $4.5 \pm 0.1$ & $4.5 \pm 0.1$ & NS \\
\hline $\begin{array}{l}\text { 4. My overall counselling experience with Interlock is/was } \\
\text { positive }\end{array}$ & $4.4 \pm 0.1$ & $4.7 \pm 0.1$ & NS* \\
\hline 5. My experience with the EAP meets/met my expectations & $4.3 \pm 0.1$ & $4.5 \pm 0.1$ & NS* \\
\hline 6. I feel this is a valuable benefit & $4.5 \pm 0.2$ & $4.8 \pm 0.1$ & NS* \\
\hline $\begin{array}{l}\text { 7. The issue(s) that led me to seek assistance interfered with my } \\
\text { home life }\end{array}$ & $4.2 \pm 0.1$ & $4.6 \pm 0.1$ & 0.014 \\
\hline 8. The assistance I received made things better at home & $4.0 \pm 0.1$ & $4.1 \pm 0.2$ & NS \\
\hline $\begin{array}{l}\text { 9. The issue(s) that led me to seek assistance interfered with my } \\
\text { work life }\end{array}$ & $3.5 \pm 0.2$ & $4.1 \pm 0.2$ & 0.034 \\
\hline 10. The assistance I received made things better at work & $3.5 \pm 0.2$ & $3.8 \pm 0.2$ & NS \\
\hline
\end{tabular}

NS = no significant difference between counselling modalities, at $P \leq 0.05$. * note that this comparison was significant when outliers were included (see Table 1).

Table 3 GAF scores comparison

\begin{tabular}{llll}
\hline GAF score* & $\begin{array}{l}\text { Online clients } \\
\text { Mean } \pm \text { SE }(n)\end{array}$ & $\begin{array}{l}\text { Face-to-face clients } \\
\text { Mean } \pm \text { SE }(n)\end{array}$ & $\begin{array}{l}\text { Overall Mean } \pm \text { SE } \\
(n)\end{array}$ \\
\hline Initial assessment & $70.3 \pm 1.5(26)$ & $67.6 \pm 0.8(101)$ & $68.1 \pm 0.7(127)$ \\
Closing assessment & $77.8 \pm 1.6(26)$ & $73.7 \pm 0.8(101)$ & $74.6 \pm 0.7(127)$ \\
Overall & $74.1 \pm 1.2(52)$ & $70.7 \pm 0.6(202)$ & \\
\hline
\end{tabular}

*ANOVA, df=3,250; $F=17.17 ; P<0.0001$.

\section{Discussion}

Barak et al. (2008), in their online counselling meta-analysis, concluded that 'Internet based therapy on the average is as effective or nearly as effective as face to face therapy' (Barak et al., 2008, p. 30). Our results support this in suggesting that our online approach is the equal of face-to-face counselling. The two caveats we explore are the need for improvements in client education and screening. Finally, we review limitations of the study.

\section{Global Assessment of Function}

With respect to the GAF scores (see Table 3), closing GAF scores were significantly higher than initial GAF scores (ANOVA, df $=1,250 ; F=43.19$; $P<0.0001$ ), indicating the effectiveness of both counselling modalities. GAF scores of online clients were significantly higher than those of 
face-to-face clients (ANOVA, $\mathrm{df}=1,250 ; F=7.98 ; P=0.005$ ). There was no statistically significant interaction between assessment timing and counselling modality (ANOVA, $\mathrm{df}=1,250 ; F=0.33 ; P=0.56$ ), indicating that there was no significant difference in the amount of client change between online and face-to-face counselling.

We can conclude, then, that although online and face-to-face clients differ in their GAF assessments, the two modalities are not different in their ability to bring about change. This takes Day and Schneider's (2002) work a step further. In their work, cybercounselling appeared promising in comparison with a control. Results of the present research suggest that cybercounselling is equivalent in impact to face-to-face work.

\section{Client Satisfaction Survey}

The results of the CSS are more complex. Of the ten questions analysed with the outliers included, five showed statistically significant differences and five did not (see Table 1). The five non-significant results were:

- 'My counsellor helps/helped me feel comfortable in discussing my problems';

- 'My counsellor's efforts and suggestions are helping/helped me develop a plan for addressing my problems';

- 'My counsellor has/had the skills and expertise to assist me with my concerns';

- 'The assistance I received made things better at home';

- 'The assistance I received made things better at work'.

It is well established that the therapeutic alliance is critical to successful counselling (Gelso and Carter, 1994; Wampold, 2000). Horvath and Luborsky (1993) identify openness, respect and a collaborative bond as essential components of the therapeutic alliance. The first three questions concerning client comfort, the establishing of a plan and the client's perception of the counsellor's skill and expertise are intended to address the building of this alliance. The lack of significant differences between the face-to-face and online modalities here suggests that online counsellors are equally effective in establishing the essential components of a working counselling relationship.

The five significant results were:

- 'My overall counselling experience with Interlock is/was positive';

- 'My experience with the EAP meets/met my expectations';

- 'I feel this is a valuable benefit';

- 'The issue(s) that led me to seek assistance interfered with my home life';

- 'The issue(s) that led me to seek assistance interfered with my work life'. 
In each case, significant results showed higher scores for the face-to-face modality.

The last two of these five questions address the issue that brought the individual to counselling: they are questions about intake. As such, they are beyond the scope of this analysis, although it is worth remarking that, despite these differences, there was no difference in clients' ratings of the impact of counselling when it came to making things better at work and home.

The other three CSS questions that showed a statistically significant difference between modalities were reanalysed with outliers removed. The revised analysis showed no statistically significant difference between the modalities (see Table 2). This result will be discussed further below. But even with the outliers remaining, it is worth pointing out that the online scores are well within the range considered acceptable in the industry. In all three cases, the clients' scores are over 4 (4 meaning 'agree' and 5 meaning 'strongly agree'). The remarkable thing about the scores here is not that the online scores are low; it is that the face-to-face scores are very high.

With the outliers removed (see Table 2), these differences disappear.

\section{Overall counselling experience}

This question takes into account everything that is part of the counselling experience. Intake is the same in both modalities, but everything else is different. In face-to-face counselling, one travels to one's counsellor's office, finds parking, speaks to a receptionist, sits in a waiting room, and so forth. None of this is likely to surprise even first-time clients.

Online counselling, however, includes logging into a secure website, coping with one's computer, dealing with possible technical issues, and so forth. It also involves practical issues like finding time to reply to one's counsellor and ensuring one has a quiet, secure space.

What this means is that many elements of the process are not only unexpected given the newness of online counselling, but are also completely out of the control of the counsellor and agency.

Given that there was no significant difference in overall counselling experience when outliers were removed, we posit that these individuals may have had problems with the online counselling process beyond the actual counselling. We recommend that online clients be comprehensively screened for their familiarity with computers and their understanding of, and comfort with, being and working online.

\section{Meeting expectations}

Online counselling is a novel approach to providing counselling services. Therapy Online was the first clinical practice to work online and we began 
our work in 1995. As such, we suggest that the difference in expectation scores without the outliers removed is related to clients not having appropriate expectations. Clearly, they expected something quite different. And were their answers here related to the inadequacy of their counsellor, we would expect to see significant differences in the answers to questions one, two and three.

Given the results, we recommend that counselling providers share with clients more details of the typical online process and what they should expect of the online counselling experience. It has been suggested elsewhere that some clinical issues are not appropriate for online counselling (Murphy and Mitchell, 1998) and Interlock already screens for these. It seems likely that some clients are also inappropriate for online counselling based on other issues. More research needs to be done to clarify this.

\section{A valuable benefit}

With the outliers removed, there is no difference between face-to-face and online clients' assessment of counselling being a valuable benefit. This, like the question about overall counselling experience, is very general, which makes it difficult to draw specific conclusions.

What can be said is that, like the question on overall counselling experience, this one likely takes into account elements of the client's beliefs and experience that are beyond the counsellor's control. It may also take into account elements of the question regarding expectations.

Given the confluence of results, we recommend providing all potential clients with details about online counselling. Although the data with outliers removed make it clear that the majority of clients who self-select for online counselling are as pleased with the experience as their counterparts who select face-to-face counselling, the goal is complete satisfaction.

\section{A note on training}

As mentioned previously, Therapy Online's counsellors receive extensive training in online counselling (Murphy et al., 2008). Previous research reviewed above is equivocal in its assessment of the value and impact of online counselling. We believe the strength of our results is related to the fact that our online counsellors receive modality-specific training.

\section{Limitations of the study}

The Client Satisfaction Survey used by Interlock has not been tested for its reliability and validity. It is possible that this has skewed the 
results. Concerns of some authors with the GAF have already been reviewed.

The high standards for the counsellors involved mitigate most of the concern about the comparative quality of the counselling done. That said, it is possible that professionals who choose to deliver online counselling are superior to others and that this explains in part the results. Human Rights rules in Canada preclude us from collecting information about counsellors' race, culture or religion. The same is true of the clients. It is possible that issues of race factor into the results.

The other differences in the two client groups, in terms of age and gender, are small but may have played a part in the results. Further research is being undertaken to explore in more depth the differences between online and face-to-face clients.

\section{Conclusion}

As a result of this work, we conclude that online counselling can be as satisfying and impactful for clients as face-to-face counselling. Counsellors can establish a comfortable environment, help clients develop plans and effectively communicate their skills to help their clients. The assistance that online counsellors provide improves clients' work and home lives. And all of this can be done as well as it is done face to face.

This research improves on previous work because our sample sizes are superior and we studied clients of the same cohort and during the same timeframe. Additional qualitative research needs to be done to explore the reasons behind some clients' outlier scores. Research that focuses on particular elements of our online counselling model that improve client outcomes is ongoing.

With respect to social work practice, this research confirms the results of reviewed research and makes plain that online counselling can provide client satisfaction and counselling outcomes as good as those in face-to-face counselling. Social workers should consider online counselling a viable modality and seek to familiarize themselves with online ethics, techniques and approaches.

Accepted: March 2009

\section{Acknowledgements}

We wish to thank Paula Cayley and Samantha Seagram for their generous assistance in providing the raw data used in the analysis for this manuscript. 


\section{References}

American Psychiatric Association (1987) Diagnostic and Statistical Manual of Mental Disorders, 3rd edn, revised (DSM-III-R), Washington, DC, American Psychiatric Association.

Bacon, S. F., Collins, M. J. and Plake, E. V. (2002) Does the Global Assessment of Functioning assess functioning?, Journal of Mental Health Counseling, 24, pp. 202-13.

Barak, A., Hen, L., Boniel-Nissim, M. and Shapira, N. (2008) 'A comprehensive review and a meta-analysis of the effectiveness of internet-based psychotherapeutic interventions', Journal of Technology in Human Services, 26, pp. 109-60.

Busseri, M. A. and Tyler, J. D. (2003) 'Interchangeability of the Working Alliance Inventory and Working Alliance Inventory, short form', Psychological Assessment, 15, pp. $193-7$.

Canadian Counselling Association (CCA) (2007) 'Code of ethics', available online at www.ccacc.ca/ECOEJAN07.pdf (retrieved 26 February 2009).

Chechele, P. J. and Stofle, G. (2003) 'Individual therapy online via e-mail and internet relay chat', in Goss, S. and Anthony, K. (eds), Technology in Counselling and Psychotherapy: A Practitioner's Guide, Houndmills, UK, Palgrave Macmillan, pp. 39-58.

Cohen, G. E. and Kerr, A. B. (1998) 'Computer-mediated counseling: An empirical study of a new mental health treatment', Computers in Human Services, 15, pp. 13-27.

Collie, K., Mitchell, D. L. and Murphy, L. J. (2000) 'Skills for on-line counseling: Maximum impact at minimum bandwidth', in Bloom, J. W. and Walz, G. R. (eds), Cybercounseling and Cyberlearning: Strategies and Resources for the Millennium, Alexandria, VA, American Counseling Association, pp. 219-36.

Cook, J. E. and Doyle, C. (2002) 'Working alliance in online therapy as compared to face to face therapy: Preliminary results', Cybercounselling and Behaviour, 5, pp. 95-105.

Day, S. X. and Schneider, P. L. (2002) 'Psychotherapy using distance technology: A comparison of face-to-face, video, and audio treatment', Journal of Counselling Psychology, 44, pp. 499-503.

Derrig-Palumbo, K. and Zeine, F. (2005) Online Therapy: A Therapist's Guide to Expanding your Practice, New York, Norton.

Endicott, J., Spitzer, R. L., Fleiss, J. L. and Cohen, J. L. (1976) 'The Global Assessment Scale', Archives of General Psychiatry, 33, pp. 766-71.

Gelso, C. J. and Carter, J. (1994) 'Components of the psychotherapy relationship: Their interaction and unfolding during treatment', Journal of Counseling Psychology, 41, pp. 296-306.

Hamburger, Y. A. and Ben-Artzi, E. (2000) 'The relationship between extraversion and neuroticism and the different uses of the internet', Computers in Human Behavior, 16, pp. 441-9.

Horvath, A. O. and Luborsky, L. (1993) 'The role of the therapeutic alliance in psychotherapy', Journal of Consulting and Clinical Psychology, 61, pp. 561-73.

Hsiung, R. C. (ed.) (2002) Etherapy: Case Studies, Guiding Principles, and the Clinical Potential of the Internet, New York, Norton.

Kraus, R., Zack, J. and Sticker, G. (eds) (2004) Online Counseling: A Handbook for Mental Health Professionals, San Diego, CA, Elsevier Academic Press.

Liebert, T., Archer, J. and Munson, J. (2006) 'An exploratory study of client perceptions of internet counselling and the therapeutic alliance', Journal of Mental Health Counselling, 28, pp. 69-84. 
Luce, K. H., Winzelberg, A. J., Zabinski, M. F. and Osborne, M. I. (2003) 'Internetdelivered psychological interventions for body image dissatisfaction and disordered eating', Psychotherapy: Theory, Research, Practice, Training, 40, pp. 148-54.

Mallen, M. J., Day, S. X. and Green, M. A. (2003) 'Online versus face to face conversations: An examination of relational and discourse variables', Psychotherapy: Theory, Research Practice Training, 40, pp. 155-63.

McMurtry, S. L. and Hudson, W. W. (2000) 'The Client Satisfaction Inventory: Results of an initial validation study', Research on Social Work Practice, 10, pp. 644-63.

Mitchell, D. L. and Murphy, L. J. (2004) 'E-mail rules! Organizations and individuals creating ethical excellence in telemental-health', in Bloom, J. and Walz, G. (eds), Cybercounseling and Cyberlearning: An ENCORE, Alexandria, VA, CAPS Press and American Counseling Association, pp. 203-17.

Murphy, L. J. and Mitchell, D. L. (1998) 'When writing helps to heal: E-mail as therapy', British Journal of Guidance and Counselling, 26, pp. 21-32.

Murphy, L. J., MacFadden, R. J. and Mitchell, D. L. (2008) 'Cybercounseling online: The development of a university-based training program for e-mail counselling', Journal of Technology in Human Services, 26, pp. 447-69.

Ontario College of Social Workers and Social Services Workers (OCSWSSW) (2008) Code of Ethics and Standards of Practice Handbook, available online at www.ocswssw.org/sections/pdf/Standards_of_Practice_Final.pdf (retrieved 26 February 2009)

Ramirez, A., Ekselius, L. and Ramklint, M. (2008) 'Axis V - Global Assessment of Functioning Scale (GAF), further evaluation of the self-report version', European Psychiatry, 23, pp. 575-9.

Reynolds, D. J., Stiles, W. B. and Grohol, J. M. (2006) 'An investigation of session impact and alliance in internet based psychotherapy: Preliminary results', Counselling and Psychotherapy, 6, pp. 164-8.

Rochland, A., Beretvas, N. and Zack, J. (2004) 'The online and face-to-face counselling attitudes scales: A validation study', Measurement and Evaluation in Counselling and Development, 37, pp. 95-111.

Startup, M., Jackson, M. C. and Bendix, S. (2002) 'The concurrent validity of the Global Assessment of Functioning (GAF)', British Journal of Clinical Psychology, 41, pp. 417-22.

Stofle, G. S. (2002) 'Chat room therapy', in R. C. Hsiung (ed.), Etherapy: Case Studies, Guiding Principles and the Clinical Potential of the Internet, New York, Norton, pp. 92-135.

Tyler, J. M. and Sabella, R. A. (2003) Using Technology to Improve Counseling Practice: A Primer for the 21st Century, Alexandria, VA, American Counseling Association.

Wampold, B. E. (2000) 'Outcomes of individual counseling and psychotherapy: Empirical evidence addressing two fundamental questions', in Brown, S. D. and Lent, R. W. (eds), Handbook of Counseling Psychology, 3rd edn, New York, John Wiley, pp. 711-39. 